\title{
Simulation modeling of integrated heat and cooling supply systems in the Far North to assess efficiency
}

\author{
Semen Vasilev ${ }^{1}$ \\ ${ }^{1}$ V.P. Larionov Institute of Physical and Technical Problems of the North, Siberian Branch, Russian Academy of Sciences, 677000 \\ Yakutsk, Russia
}

\begin{abstract}
This paper proposes the creation of an integrated heat and cooling system in the city of Yakutsk. A classic version of district cooling (DC) with the use of absorption chillers is considered. The operation of the integrated power system was simulated for 3 months in the summer of 2019. The simulation results showed the presence of a sufficient amount of waste heat for the entire time of the DC operation, even for the maximum possible cooling demand. Calculations showed the possibility of reducing electricity consumption in the city from 0.8 to $20.0 \%$. Primary economic indicators showed the possible economic success of such a project, if there is sufficient demand for cold.
\end{abstract}

\section{Introduction}

Global and Russian Energy outlook 2019, developed by the Energy Research Institute of the Russian Academy of Sciences (ERI RAS) and Moscow School of Management Skolkovo, shows general trends in the development of the world energy in the direction of a multiple increase in the generation of renewable energy sources and the displacement of fossil fuels. This is facilitated by the state energy policy of the developed countries of the world on decarbonization and technology development.

This outlook considers three development scenarios: conservative, innovative and energy transition. The scenarios differ in the speed of technology development, the level of international transfer of modern technologies and the focus of the energy policy of the countries of the world in order to decarbonize. The scenario forecast represents a decrease in Russia's export revenues for all scenarios due to an increase in carbon-free types of energy in the global energy sector. A decline in exports will slow down the average annual growth rate of Russia's gross domestic product (GDP) to $1.7 \%$ in the conservative and innovative scenarios and to $0.6 \%$ in the energy transition by 2040 . Also, ERI RAS describes an alternative option for using technological progress to accelerate the development of the country's economy Energy transition with adaptation. This option requires a large-scale implementation of energy efficient technologies and intensification of energy saving measures. According to estimates, the development of interior production and energy efficiency can increase the GDP growth rate up to $2.7 \%$. The development of scientific and technological progress can be ensured under three conditions: a gradual increase in interior gas prices to the level of equal profitability for all consumers, except for the population; reduction in the price of capital from $8-9 \%$ at present to $6-7 \%$; introduction of a price for $\mathrm{CO}^{2}$ emissions. According to the authors, without the implementation of adaptation measures, Russia will slow down the rate of economic growth for all scenarios [1].

Energy transition with adaptation creates new challenges for the Russian energy sector. Modern development trends lead to the creation of integrated intelligent energy systems (IIES) and to the formation of a new paradigm in the energy sector, requiring structural and technological transformations [2]. In Russia, this issue is dealt with by the Melentiev Energy Systems Institute of the Siberian Branch of the RAS (ESI SB RAS). They carried out work on structuring the problems of the development of IIES in Russia. Also, they performed mathematical descriptions of problems and illustrated examples of researching emergency situations, taking into account the joint functioning of power systems of various types [3]. The challenges of the new time and integration trends in the energy sector require the development of a technology for the joint design and operation of IIES taking into account Russian conditions. The transition to the IIES is a complex multidimensional problem requiring methodological re-equipment [4].

For these reasons, the issues of increasing energy efficiency and energy saving, as well as the choice of promising technologies adapted to the conditions of Russia, become especially significant. One of the promising options for increasing the energy efficiency of the energy system in Russia is the use of the technology of integrated heat and cooling supply systems. The cold climate, long distances, the presence of a large volume of fossil fuels predetermined the development of the Russian energy system towards the use of large thermal power plants using fossil fuels. The generation of electricity during summer from thermal power plants creates a significant amount of waste heat. The presence of piping systems for district heating and waste heat are indicators of the effectiveness of the technology of district cooling based on absorption chillers for 
generating cold in summer. Using waste heat as an energy source for air conditioning instead of electricity can increase the energy efficiency of plants in summer as well as reduce $\mathrm{CO} 2$ emissions. Such technology can become especially relevant in the scenario of the Energy Transition with adaptation. Examples of economically successful implementation of DC in European cities with relatively high price of gas and the low price of capital confirm this [5].

Such a system can be especially effective in regions with a harsh continental climate, with cold winters and hot summers. This paper discusses the implementation of an integrated heat and cooling supply system in the city of Yakutsk, which will improve the energy efficiency of the system in summer. For these purposes, a simulation of the system was carried out and the primary technical and economic parameters were calculated.

\section{Object of study characteristics}

The power system of the city of Yakutsk, the Republic of Sakha (Yakutia) was chosen as the object of the study. The power system consists of two thermal power plants Yakutskaya GRES with an installed capacity of $368 \mathrm{MW}$, Yakutskaya GRES Novaya with an installed capacity of $193.5 \mathrm{MW}$, main heat supply networks with a length of $76 \mathrm{~km}$ with an average diameter of $500 \mathrm{~mm}$, a central heating station (CHS), distribution pipeline heating systems with a length of 167 $\mathrm{km}$ with an average diameter of $125 \mathrm{~mm}$ and consumers of cold. A total of 1,099 different buildings were modeled, divided into 33 quarters. Hourly simulations were carried out for 3 summer months of 2019: June, July, August. The simulation time was 2208 hours. These power plants provide electricity to the central industrial group of the central and outlying regions of the Republic of Sakha (Yakutia) [6].
This paper considers the possibility of using the classical technology of DC with absorption chillers in the power system of Yakutsk. Waste heat from 2 power plants is transferred through the existing heating main pipelines. Absorption chillers located in central chilling stations (CCS) generate cold (water with a temperature of 6 to $\left.13{ }^{\circ} \mathrm{C}\right)$ using hot water $\left(90-150{ }^{\circ} \mathrm{C}\right)$ as an energy source. For the convenience of modeling, the CCS are located near to the existing CHS. New cold water piping systems are being built in parallel with existing heat distribution networks (Figure 1). Air conditioning in buildings is carried out using chiller-fan coil technology.

\section{Modeling}

The hourly operation of the energy system is simulated. The hourly parameters of the operation of the stations, the amount of waste heat, the cooling demand were calculated by various methods and summarized in a general program, taking into account their interactions. The obtained simulation results are used to assess the efficiency of the integrated system.

\subsection{Waste heat}

In Yakutsk, two thermal power plants with combined generation of electricity and heat operate. Equipment composition for 2019:

- Yakutskaya GRES (YAGRES)- the installed capacity is $368 \mathrm{MW}$, the turbine park includes 12 gas turbine units with 8 waste heat boilers PSV-2. Gas turbine units (GTU) include 3 types of turbines: GTE-45, GT-35 and GTG-12V.

- Yakutskaya GRES Novaya (YAGRES Novaya) installed capacity $193.48 \mathrm{MW}$, the turbine park includes 4 gas turbines with LM 6000 PF DF turbines with 3 waste heat boilers KV-GM-116.

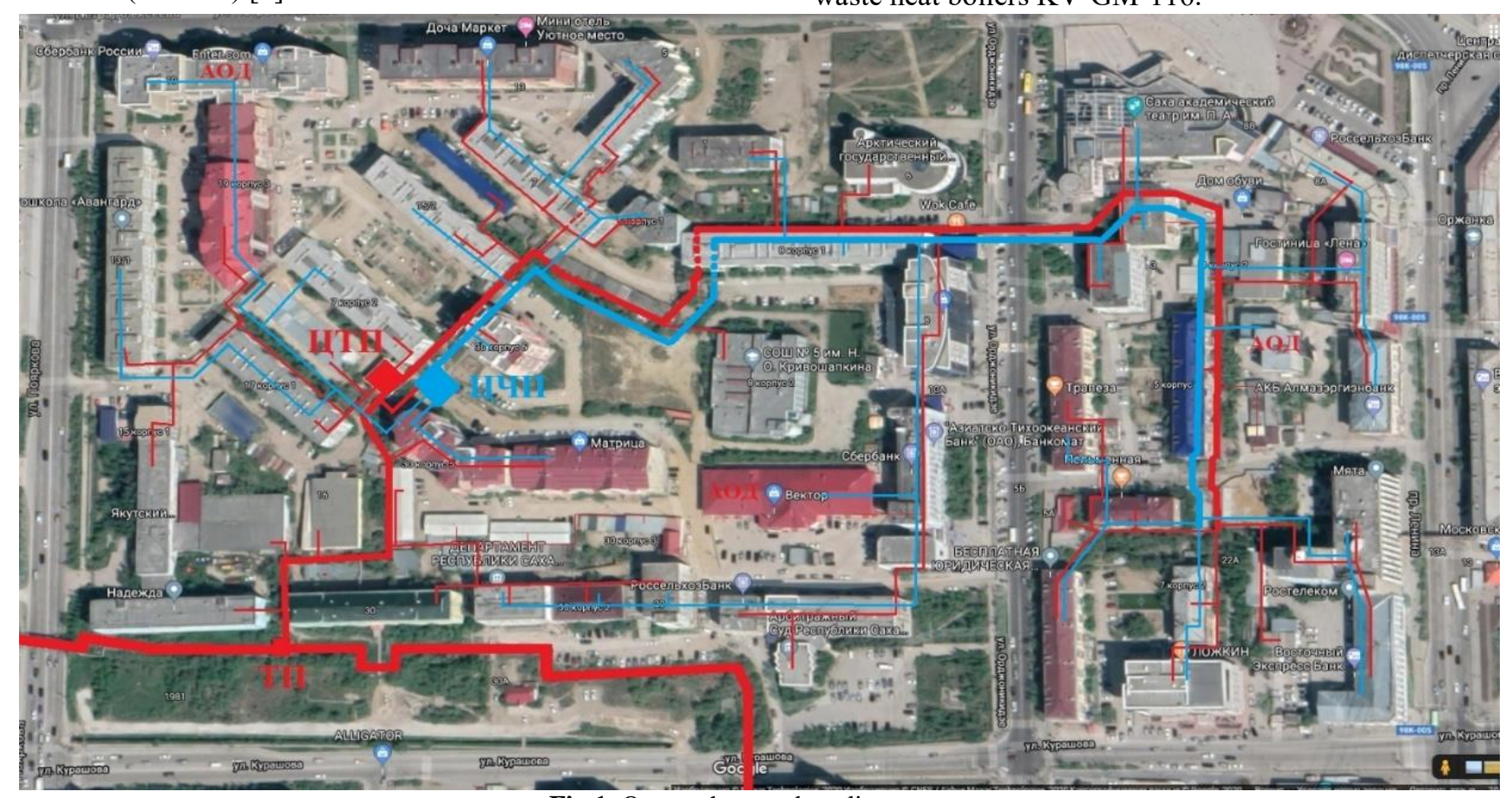

Fig 1. Quarter heat and cooling system

\subsubsection{Waste heat of the Yakutskaya GRES}

Hourly recovering heat from operating gas turbine plants is calculated according to the energy characteristics of 
the turbines (Figure 2 and Figure 3) depending on the hourly electrical load of the power plant turbines. The waste heat is calculated with the deduction of the heat load for summer time (see table 1) according to the formula (1). Gas turbine units with GTG-12V turbines do not produce thermal power [7].

$$
Q_{\text {heat }}^{\text {waste }}=Q_{\text {heat }}^{\text {recoving }}-Q_{\text {load }}^{\text {heat }}
$$

Table 1. Average heat load in summer by stations, Gcal/h

\begin{tabular}{|c|c|c|c|}
\hline \multirow{2}{*}{$\begin{array}{c}\text { Power } \\
\text { station }\end{array}$} & \multicolumn{3}{|c|}{2019} \\
\cline { 2 - 4 } & June & July & August \\
\hline YAGRES & 32 & 37 & 40 \\
\hline $\begin{array}{c}\text { YAGRES } \\
\text { Novaya }\end{array}$ & 17 & 0 & 11 \\
\hline
\end{tabular}

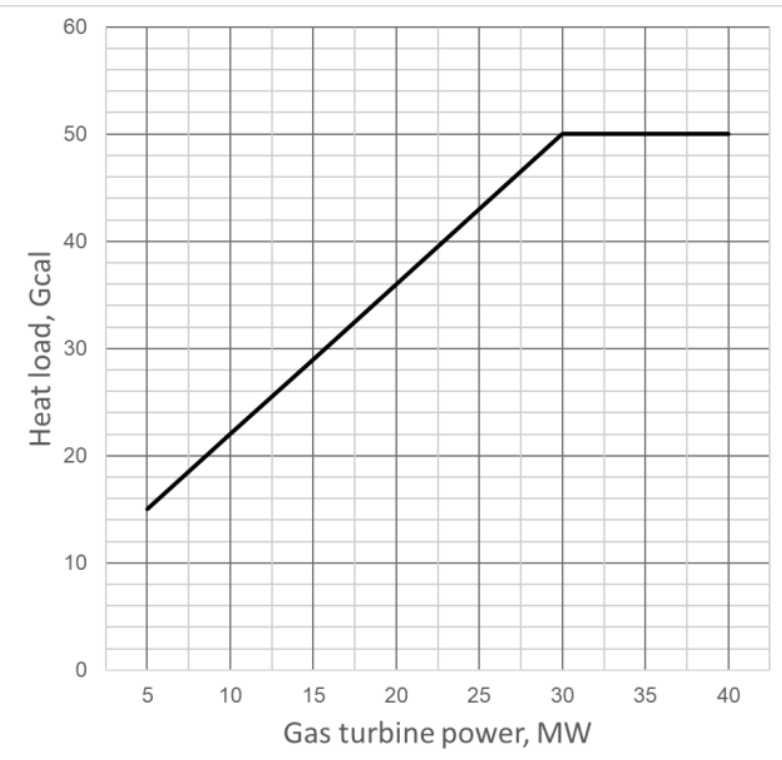

Fig 2. Dependence of heat load on electrical power of GT-35

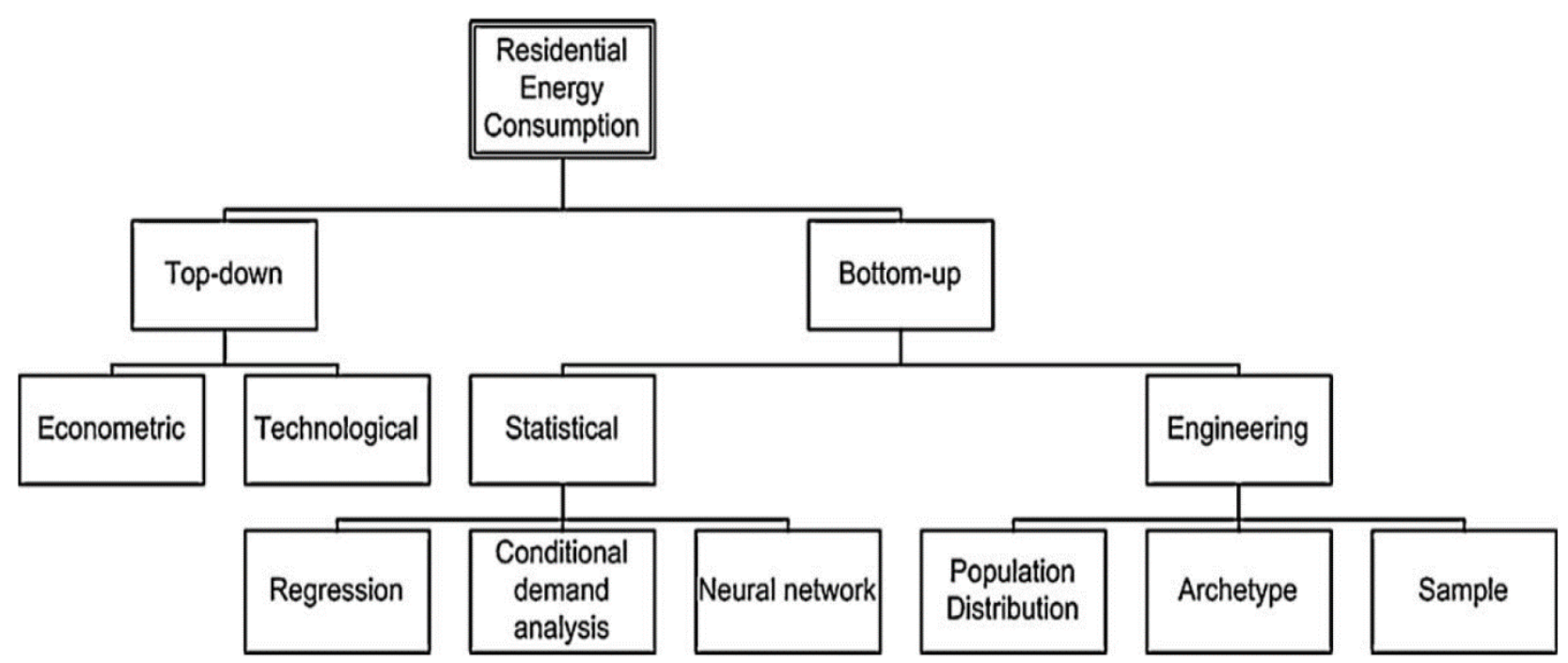

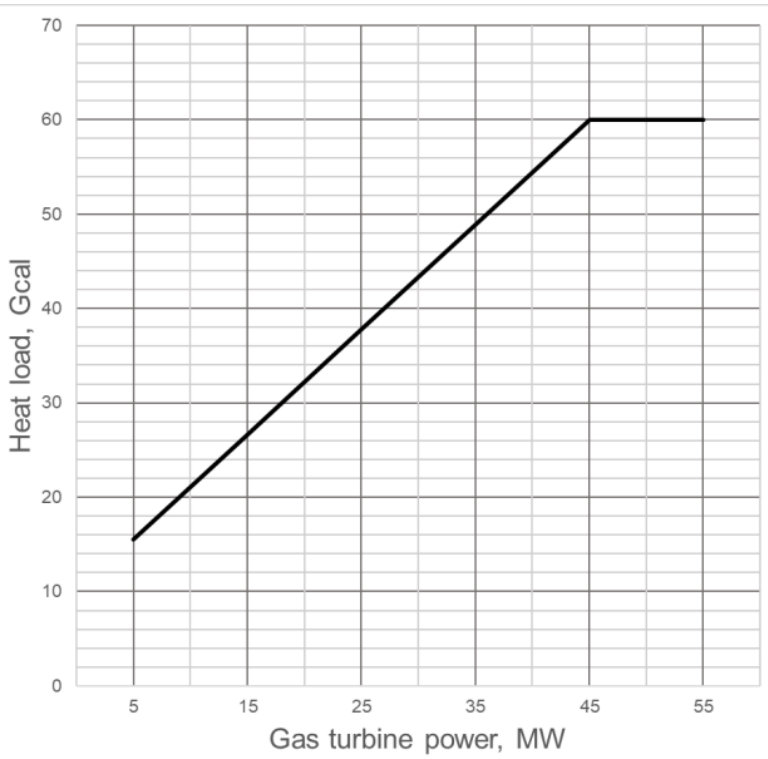

Fig 3. Dependence of heat load on electrical power of GTE-45

\subsubsection{Waste heat from YaGRES Novaya}

Recovering heat from LM 6000 PF DF turbines at YaGRES Novaya is calculated using the indicator of the specific heat consumption for the production of electrical energy $\mathrm{n}=8649 \mathrm{~kJ} /(\mathrm{kW} \cdot \mathrm{h})$ depending on the hourly electrical load of the gas turbine power plants. Waste heat from the power plant is calculated using formula (1).

\subsection{Cooling demand simulation}

\subsubsection{Modeling method}

There are many methods for estimating the energy demand of buildings on a city-wide basis, but not all of them can explicitly account for every building in the city and describe the hourly or less time energy demand.

Fig 4. Top-down and bottom-up modeling techniques for estimating regional or national energy consumption in the residential sector. Source [7]

Methods for estimation of the energy consumption of buildings fall into two categories (Figure 4). Top-down approaches use data on the total energy consumption of a district or city and other relevant variables to attribute 
energy consumption to the characteristics of the entire sector. In other words, top-down models study the city as an object according to its general characteristics. Since the city's components are not considered separately, topdown approaches cannot explicitly account for the energy requirements of each individual building.

Bottom-up approaches take into account the consumption of each building using statistical and engineering methods. Statistical methods are based on large amounts of different data obtained from field measurements, data from energy suppliers, government publications and surveys. Engineering methods calculate the energy demand for each building power system using engineering models.

Consequently, only engineering methods can simulate the consequences of important changes, such as technological breakthroughs, large-scale repairs or changes in population consumption, due to their high level of detail and their physical models, as opposed to a statistical approach based on historical data [8].

For this work, the engineering method "bottom-up" using archetypes was chosen. The choice is based on the previously described advantages, as well as the lack of statistical data on cold consumption in Yakutsk and the lack of possibility of carrying out field tests.

\subsubsection{Accepted simplifications}

Several assumptions are made to simplify the modeling steps and reduce the calculation time. The following factors are not taken into consideration:

- Influence of the urban environment, in particular, the effect of a heat island, an increase in the average temperature inside cities;

- Obstacles that reduce the flow of solar energy;

- Reflective surfaces affecting the balance of surface energy;

- City morphology, which changes convective heat exchanges and air flows around buildings;

- Complex geometry of buildings. For simplicity of modeling, all buildings are divided into free-standing rectangular parts.

\subsubsection{Hourly cooling demand simulation}

The simulation is performed using the eQuest program based on the DOE-2 program. DOE-2 software was developed by James J. Hirsch \& Associates (JJH) in collaboration with Lawrence Berkeley National Laboratory (LBNL). EQuest operates in accordance with ASHRAE 90.1, California Title 24, etc.

Hourly cooling demand modeling is performed depending on the ambient temperature, solar insolation, direction, height, area, internal heat inflows, thermal conductivity of structures, etc. (Figure 5). The average statistical indicators of meteorological data for the city of Yakutsk were used [9].

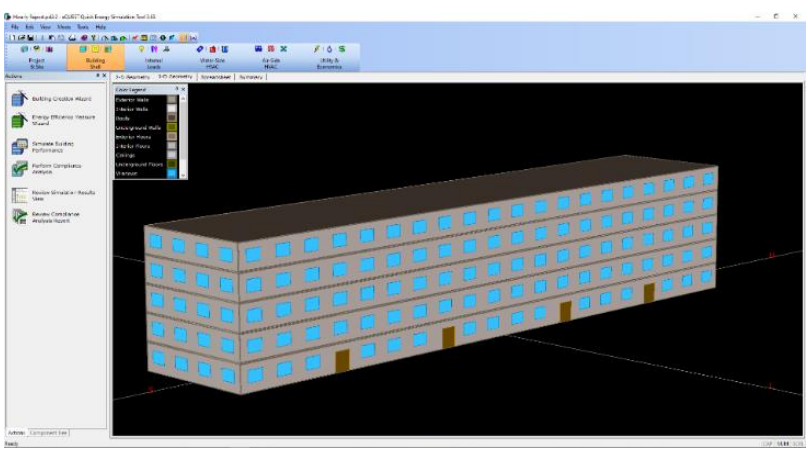

Fig 5. Building modeling example

Consumers are divided into 5 archetypes (Table 2). For each archetype, hourly detailed modeling was carried out for 4 orientations of the building relative to the cardinal points: north, northeast, northwest, east. In total, the hourly distribution of the demand of 20 buildings has been developed (Figure 6). The obtained graphs of the cooling demand are distributed for all buildings in proportion to their area of premises, according to their archetype and orientation.

Table 2. Archetypes

\begin{tabular}{|c|c|c|}
\hline № & Archetypes & $\begin{array}{c}\text { Average cold } \\
\text { power, W/m }\end{array}$ \\
\hline 1 & Residential building & 90 \\
\hline 2 & Office & 219 \\
\hline 3 & Hospital & 87 \\
\hline 4 & Retail & 132 \\
\hline 5 & Hotel & 66 \\
\hline
\end{tabular}

\subsection{Modelling piping systems}

Heat losses in main pipelines in summer are taken as the maximum possible $20 \%$ [10]. Losses in distribution district cooling networks are also taken at a maximum value of $2 \%$ [11].

\subsection{Modeling the operation of an integrated heat and cooling supply system}

Modeling of the power system operation is performed in the Simulink graphical programming environment based on MATLAB.

\subsubsection{Cooling demand scenarios}

Five scenarios of cooling demand are considered - from $20 \%$ to $100 \%$ of the maximum possible total demand of buildings. The maximum cooling demand is equal to the connection of all 1099 buildings to the DC located near the main heat supply networks. The scenarios differ only in the total volume of the cooling demand. Various options for connecting buildings in the DC, as well as their possible partial connection are not taken into account because of this simplification. 


\subsubsection{Waste heat estimation}

Hourly cooling demands of all buildings in Yakutsk, located near the main heating pipelines, were added to the model. The simulated hourly total cooling demand is compared with the hourly value of waste heat, taking into account losses in the networks and parameters of the main equipment (Table 3 ). Residual waste heat $\Delta Q_{\text {heat }}^{\text {waste }}$ calculated by the formula (2) (Figure 7).

$\Delta Q_{\text {heat }}^{\text {waste }}=Q_{\text {heat }}^{\text {waste }}-\mathrm{COP} \cdot Q_{\text {cooling }}^{\text {demand }}-Q_{\text {main pipelines }}^{\text {losses }}-$
$Q_{\text {distribution pipelines }}^{\text {losses }}$

Where, COP - coefficient of performers, $Q_{\text {cooling }}^{\text {demand }}$ - cooling demand, $Q_{\text {main pipelines }}^{\text {losses }}$ - heat loss in main

Percent, $\%$ pipelines, $Q_{\text {distribution pipelines }}^{\text {losses }}$ - heat loss in cooling distribution pipes.

The calculation of the residual waste heat made it possible to establish that the amount of waste heat for the entire simulation period is sufficient to cover the maximum possible cooling demand (Table 5). The maximum value of the waste heat shortage is $265.7 \mathrm{Gcal}$.

Table 3. Main equipment parameters

\begin{tabular}{|c|c|}
\hline Energy efficiency & Value \\
\hline Split systems, EER & 3 \\
\hline Absorption chillers, COP & 0,78 \\
\hline
\end{tabular}

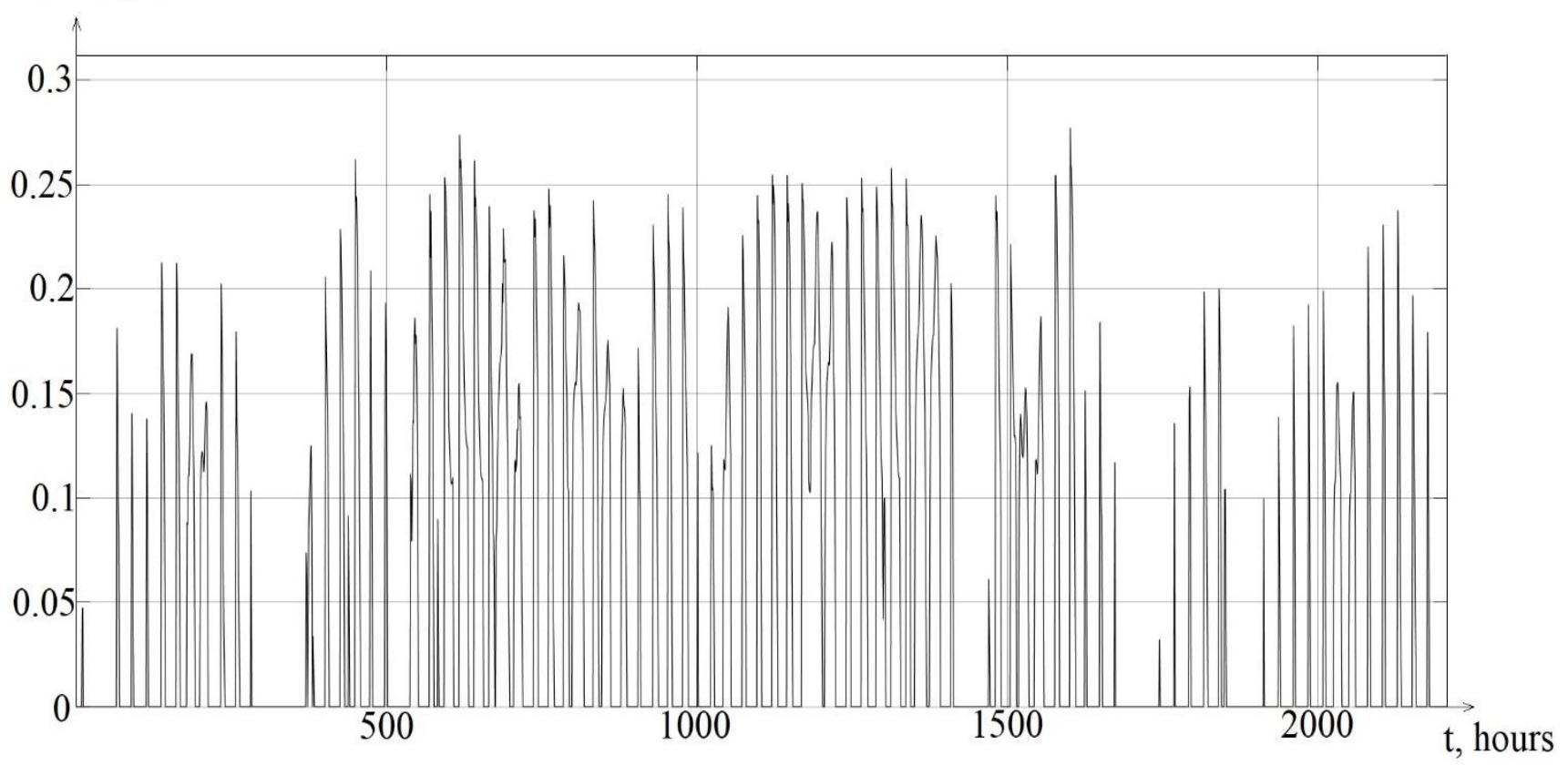

Fig. 6. Graph of the percentage distribution of the cooling demand of a residential building

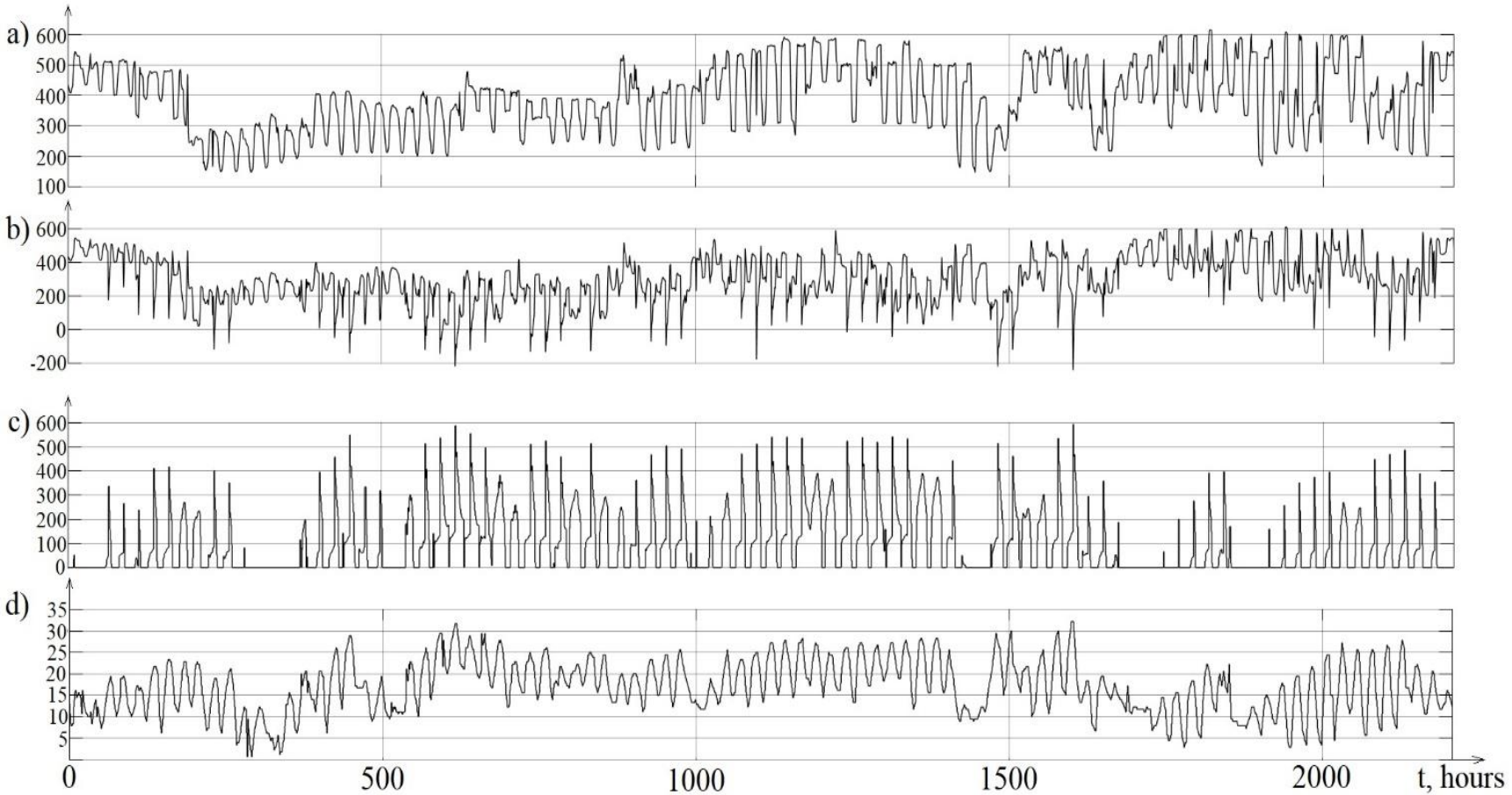

Fig. 7. a) $Q_{\text {heat }}^{\text {waste }}$ waste heat from 2 power plants, Gcal. b) $\Delta Q_{\text {heat }}^{\text {waste }}$ excess waste heat at $100 \%$ cooling demand, Gcal. c) total $100 \%$ cooling demand, Gcal. d) ambient temperature, ${ }^{\circ} \mathrm{C}$. 


\subsubsection{Comparison of cooling options}

To assess the energy saving potential of integrated systems in Yakutsk, two options for cooling are compared. DC supply based on absorption chillers and split-system local air conditioners. Possible reduction of electricity consumption for work is calculated by the formula (3).

$$
\Delta E_{\text {reduction }}=\Sigma E_{\text {split-system }}-\Sigma E_{O N}
$$

where, $\Delta E_{\text {reduction }}-$ this is a possible reduction in electricity generation, $\Sigma E_{\text {split-system }}$ - the amount of electricity consumption for the operation of local split

systems, $\Sigma E_{\mathrm{ON}}-$ own needs of DC

Electricity consumption for the operation of DC is calculated as the sum of electricity consumption of circulation pumps of main pipelines, absorption chillers and pumps of cooling distribution networks. Equipment parameters are shown in Table 4.

Table 4. DC equipment parameters

\begin{tabular}{|c|c|}
\hline Equipment & Power, kWt \\
\hline Main heat pipelines pumps & 7315 \\
\hline Absorption chillers & 684 \\
\hline Cooling distribution pipelines pumps & 990 \\
\hline
\end{tabular}

The obtained results of the percentage of possible energy savings in relation to the electrical load of Yakutsk for 3 months of 2019 are reflected in Table 5. The consumption of already installed air conditioners is not deducted due to the lack of statistical data.

\subsection{Primary technical and economic parameters of the district cooling}

The calculation was carried out according to the standard methodology for assessing the effectiveness of investment projects [12]. The revenue of the DC is calculated as the savings in electrical energy for the operation of split-system air conditioners. The electricity tariff in 2019 for the city of Yakutsk was 6.49 rubles / $\mathrm{kWh}$. Loan interest and waste heat price are not included. The obtained calculation results are shown in Table 6 .

\section{Conclusions}

The results showed the presence of a sufficient amount of waste heat to provide cold to all consumers in Yakutsk located near the main pipeline heating systems, throughout the entire simulation period. The introduction of integrated systems of heat and cooling supply, according to the initial assessment, can significantly reduce the total consumption of electricity by consumers in Yakutsk. Initial calculations indicate the possible economic success of the project, even under current market conditions, if there is sufficient demand for cold. In this study, a comparative assessment of energy efficiency is made only for possible energy savings. In the future, it is planned to carry out more detailed calculations. The relevance of the introduction of the technology of integrated systems of heat and cold supply is confirmed not only by the results of modeling, but also by the main trends in the development of the world energy towards decarbonization, globalization, the introduction of quotas for $\mathrm{CO} 2$ emissions, etc.

Table 5. System metrics for demand scenarios

\begin{tabular}{|c|c|c|c|c|c|}
\hline Parameters & Scenario №1 & Scenario №2 & Scenario №3 & Scenario №4 & Scenario №5 \\
\hline Cooling demand, $\%$ & 20 & 40 & 60 & 80 & 100 \\
\hline $\begin{array}{l}\text { Percentage of waste heat available } \\
\text { for system operation, } \%\end{array}$ & 100 & 100 & 100 & 99,87 & 99,42 \\
\hline Possible electricity savings, ths kWh & 1424 & 12020 & 22610 & 33200 & 43800 \\
\hline $\begin{array}{c}\text { Percentage of possible electricity } \\
\text { savings, } \%\end{array}$ & 0,8 & 6,4 & 11,4 & 15,9 & 19,9 \\
\hline
\end{tabular}

Table 6. Technical and economic indicators of the district cooling system

\begin{tabular}{|c|c|c|c|c|c|c|}
\hline № & Indicators & Scenario №1 & Scenario №2 & Scenario №3 & Scenario №4 & Scenario №5 \\
\hline 1 & Payback period, year & 53 & 21 & 15 & 14 & 13 \\
\hline 2 & Operating costs, thousand RUB & 63,61 & 76,62 & 85,79 & 93,57 & 133,92 \\
\hline 3 & Investments, million RUB & 1475,38 & 2090,96 & 2531,47 & 3203,05 & 3357,94 \\
\hline 4 & Proceeds, thousand RUB & 69,70 & 139,47 & 209,17 & 278,94 & 348,64 \\
\hline 5 & $\begin{array}{l}\text { Cooling demand, thousand } \\
\mathrm{kWh} / \text { year }\end{array}$ & 10740 & 21490 & 32230 & 42980 & 53720 \\
\hline 6 & Tariff, RUB/kWh & 6,49 & 6,49 & 6,49 & 6,49 & 6,49 \\
\hline 7 & $\begin{array}{l}\text { Profit contribution, thousand } \\
\text { RUB/year }\end{array}$ & 6,10 & 62,86 & 123,38 & 185,37 & 214,73 \\
\hline 8 & $\begin{array}{l}\text { Rental fee for } 2.5 \mathrm{~kW} \text { of cold, } \\
\text { RUB/year }\end{array}$ & 2250,2 & 2251,2 & 2250,8 & 2251,2 & 2251,0 \\
\hline 9 & $\begin{array}{l}\text { Split system electricity bill, } \\
\text { RUB \year }\end{array}$ & 2596,0 & 2596,0 & 2596,0 & 2596,0 & 2596,0 \\
\hline
\end{tabular}




\section{References}

1. Global and Russian Energy outlook 2019. The Energy Research Institute of the Russian Academy of Sciences (ERI RAS), Moscow School of Management SKOLKOVO, (2019)

2. Voropai N.I., Stennikov V.A., Barakhtenko E.A. Methodological principles of constructing the integrated energy supply systems and their technological architecture. Journal of Physics: Conference Series. (2018). Vol.1111. No.1. ID: 012001. doi: 10.1088/1742-6596/1111/1/012001

3. Nikolai Voropai, Valery Stennikov, Sergey Senderov, Evgeny Barakhtenko, Oleg Voitov, and Alexander Ustinov. Modeling of Integrated Energy Supply Systems: Main Principles, Model, and Applications // Journal of Energy Engineering. Vol. 143, Issue 5 (October 2017)

4. Voropai N.I., Stennikov V.A., Barakhtenko E.A. Integrated Energy Systems: Challenges, Trends, Philosophy // Studies on Russian Economic Development, Vol. 28, No. 5, pp. 492-499. (2017)

5. Best practice examples of District Cooling systems. Rescue (2013)

6. Energy strategy of the Republic of Sakha (Yakutia) for the period up to 2030. Yakutsk-Irkutsk: "Yakutia" Media Holding, 328 p. (2010)

7. Materials of PJSC «Yakutskenergo»

8. Lukas G. Swan, V. Ismet Ugursal Modeling of enduse energy consumption in the residential sector A reviewof modeling techniques // Renewable and Sustainable Energy Reviews. 2009. Volume 13. P. 1819-1835

9. EnergyPlus weather data (2021) 〈https://energyplus.net/weather〉

10. Estimation of summer thermal losses in heating networks. A.N. Kudryashov, V.V. Elizarov, E.Yu. Samoilova. Irkutsk State Technical University, Vestnik INRTU №10 (69) (2012)

11. Energy Losses Study on District Cooling Pipes. Marius Alexandru Calance. Faculty of engineering and sustainable development Department of Building, Energy and Environmental Engineering. 2014

12. P.L. Vilensky, V.N. Livshits, S.A. Smolyak. Evaluation of the efficiency of investment projects. Moscow Publishing House "Delo". (2002) 